\title{
Dr Thornton Brown
}

\author{
AN APPRECIATION
}

With the death of Emeritus Editor Dr Thornton Brown, the British Volume has lost one of its oldest friends and supporters. The appearance of his Obituary in the November 2000 issue of the American Volume of the Journal of Bone and Joint Surgery stimulated me to record some personal reminiscences of this quiet and unassuming man.

I first met him in 1966 when I went to Boston for a year on an orthopaedic fellowship at Harvard University and Massachusetts General Hospital. Before my departure I had been working at the London Hospital as one of the last registrars of Sir Reginald Watson-Jones, who was then still Editor of the British Volume which was produced from his rooms at 82 Portland Place. He gave me a letter of introduction to his American counterpart and that was how we came into contact. Dr Brown invited me to the Journal Office, then based in the Countway Medical Library, which proved to be something of a 'culture shock' after the opulent, but crowded, surroundings of the British office.
I was shown around a spacious, air-conditioned working area, populated it seemed by many more staff than in the London office, and with the backing of a full modern medical library in the same building. I was equally impressed by the man, who seemed very relaxed and informal, quite unlike the stiff, severe, senior figure whom I had expected to meet. He provided me with much help and advice on publishing research findings during the rest of my year and we remained in friendly contact after my return to the UK. Any subsequent encounters at overseas meetings brought instant recognition, a warm greeting, and an enquiry on the state of my progress. Others have spoken of his abilities as an Editor and I know that he was held in high esteem by his clinical colleagues for his fair-mindedness and integrity. I shall remember him for the kindness and interest which he showed to a young British trainee in what was then a very foreign land. 